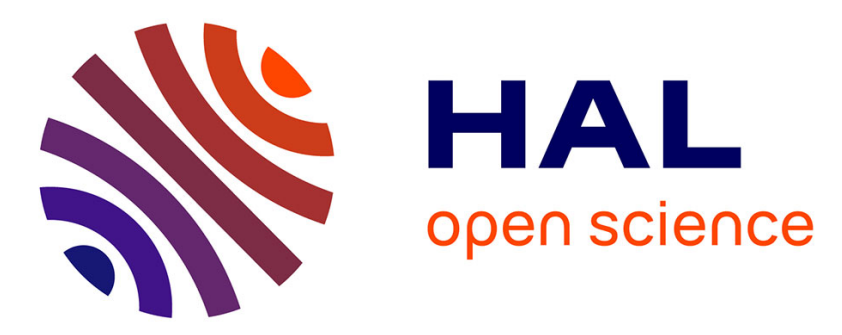

\title{
Acoustical properties of the polymer liquid crystal (P41)35 in the nematic, smectic A and glass phases
}

Ludovic Benguigui, P. Ron, F. Hardouin, Monique Mauzac

\section{To cite this version:}

Ludovic Benguigui, P. Ron, F. Hardouin, Monique Mauzac. Acoustical properties of the polymer liquid crystal (P41)35 in the nematic, smectic A and glass phases. Journal de Physique, 1989, 50 (5), pp.529-538. 10.1051/jphys:01989005005052900 . jpa-00210935

\section{HAL Id: jpa-00210935 https://hal.science/jpa-00210935}

Submitted on 1 Jan 1989

HAL is a multi-disciplinary open access archive for the deposit and dissemination of scientific research documents, whether they are published or not. The documents may come from teaching and research institutions in France or abroad, or from public or private research centers.
L'archive ouverte pluridisciplinaire HAL, est destinée au dépôt et à la diffusion de documents scientifiques de niveau recherche, publiés ou non, émanant des établissements d'enseignement et de recherche français ou étrangers, des laboratoires publics ou privés. 
Classification

Physics Abstracts

$62.60-64.70 \mathrm{M}$

\title{
Acoustical properties of the polymer liquid crystal (P41 $)_{35}$ in the nematic, smectic $A$ and glass phases
}

\author{
L. Benguigui $\left({ }^{1}\right)$, P. Ron $\left({ }^{1}\right)$, F. Hardouin $\left({ }^{2}\right)$ and M. Mauzac $\left({ }^{2}\right)$ \\ ( $\left.{ }^{1}\right)$ Solid State Institute, and Department of Physics, Technion-Israel Institute of Technology, \\ 32000 Haifa, Israel \\ $\left.{ }^{2}\right)$ Centre de Recherches Paul-Pascal, Domaine Universitaire, 33405 Talence, France
}

(Reçu le 23 septembre 1988, accepté le 23 novembre 1988)

\begin{abstract}
Résumé. - Nous avons mesuré la vitesse et l'absorption des ondes acoustiques longitudinales dans le polymère cristal liquide polymethylsiloxane $(\mathrm{P} 41)_{35}$ depuis $106^{\circ} \mathrm{C}$ jusqu'à $-6^{\circ} \mathrm{C}$. La phase nématique est caractérisée par un comportement viscoélastique et un temps de relaxation relativement grand. Nous n'avons pas observé d'absorption critique ni à la transition isotropenématique ni à la transition nématique-smectique $\mathrm{A}$. Dans la phase smectique $\mathrm{A}$, nous avons observé une croissance régulière de l'anisotropie des vitesses et des coefficients élastiques $C_{11}, C_{13}$, et $C_{33}$. La transition vers l'état vitreux est accompagnée par un maximum de l'absorption, aux environs de $40^{\circ} \mathrm{C}$. Les quatre constantes élastiques ont été mesurées : $C_{11}, C_{33}$ et $C_{44}$ croissent quand la température décroît, mais $C_{13}$ décroît.
\end{abstract}

\begin{abstract}
The longitudinal acoustical velocity and the absorption were measured in the polymer liquid crystal polymethylsiloxane $(\mathrm{P} 41)_{35}$ from $106^{\circ} \mathrm{C}$ down to $-6{ }^{\circ} \mathrm{C}$. The nematic phase is characterized by a viscoelastic behavior and a relatively large relaxation time. We do not observe any critical absorption nor at the isotropic-nematic transition neither at the nematicsmectic A transition. In the smectic A phase, we observe a regular increase of the velocity anisotropy and of the elastic coefficients $C_{11}, C_{13}$ and $C_{33}$. The transition toward the glass phase is marked by a strong maximum in the absorption around $40^{\circ} \mathrm{C}$. The four elastic constants $C_{11}, C_{13}, C_{33}$ and $C_{44}$ were measured : $C_{11}, C_{33}$ and $C_{44}$ increase if the temperature decreases but $C_{13}$ decreases.
\end{abstract}

\section{Introduction.}

We present in this paper studies of the acoustical properties of the comb like polymer liquid crystal polymethylsiloxane $\left(\mathrm{P}_{41}\right)_{35}$ in order to provide a contribution to the understanding of the dynamic properties. One of the major problems in the polymer liquid crystals is to understand the role of the backbone. The problem of the backbone conformation has recently been studied by means of neutron scattering [1]. In the case of the dynamics very few studies have been performed and this motivated us to undertake acoustical measurements.

The acoustic properties of the liquid crystal are related to the symmetry of the liquid crystal ordering [2]. Thus we do not expect qualitative differences between polymer liquid crystals 
and monomer liquid crystals, except may be in the glassy state which is more frequently observed in the case of polymer liquid crystals. However, we do expect a quantitative influence of the backbone on the dynamic properties. In particular, we found that the relaxation time is larger than that measured in the monomer liquid crystal, making the nematic characterized by a viscoelastic behavior at a relatively low frequency of $2 \mathrm{MHz}$. We do not observe the well known increase of the sound absorption at the isotropic-nematic (IN) and at the nematic-smectic A(NA) transitions at this frequency. In the smectic A, it seems that the properties are connected with the structural evolution toward the glassy state in agreement with the results of Kruger et al. [3]. It is very likely that if one wants to study the critical phenomena as in the monomer liquid crystal, one has to work at much lower frequency than $2 \mathrm{MHz}$.

The sample we studied has the following formula:

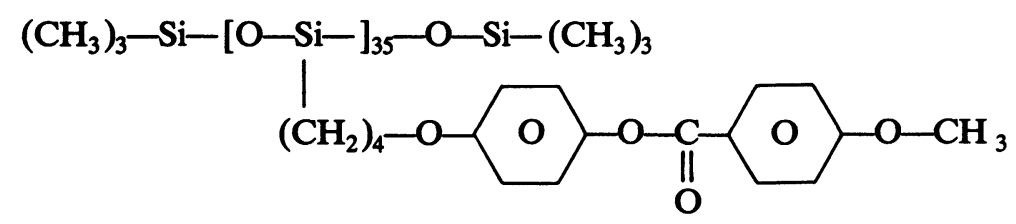

and it exhibits the following sequence of phases [4] : Glass- $7^{\circ} \mathrm{C}-\mathrm{SmA}-72{ }^{\circ} \mathrm{C}-\mathrm{N}-101{ }^{\circ} \mathrm{C}$-Iso.

To measure the longitudinal velocity we used the standard echo technique and the phase difference method (for more details see Ref. [5]). Since the absorption is relatively large, we observe only the transmitted pulse, the echos being too small to get a reliable value of the absorption. Thus we get only the relative value of the absorption in measuring the amplitude of the received signal. Preliminary results have been recently published [5].

\section{Experimental results.}

For a good understanding of the subject we must detail the results in the two following ranges: the isotropic and nematic phases, and the smectic $\mathrm{A}$ and glass phases.

2.1 The ISOTROPIC AND NEMATIC PHASES. - In the isotropic and the nematic phases we were able to perform measurements at $2,3.5,7.5$ and $9.3 \mathrm{MHz}$. We give in the figures 1 and 2 the variation of the sound velocity $V_{\boldsymbol{I}}$ and $V_{\perp}$ and the absorption $D_{\perp}$ and $D_{\|}$as a function of the temperature, at $2 \mathrm{MHz}$. The subscript $\perp(\|)$ denotes the case where the wave vector is perpendicular (parallel) to the molecular director. The isotropic-nematic phase transition is easily detected by the appearance of the anisotropy in the velocity and in the absorption. The NA transition is only marked by a break in the slope in $V(T)$. It seems that $D(T)$ is the sum of two contributions: one exhibiting a maximum and the second, that we can call the background which increases regularly when $T$ decreases. The absorption increases if $T$ decreases at all the frequencies. Only at $2 \mathrm{MHz}$ and $3.5 \mathrm{MHz} D_{\perp}$ and $D_{\|}$exhibit a maximum. We suppose that for the other frequencies, the contribution to $D$ which shows this maximum is much lower than the background and it is not seen.

The dependence of the velocity with the frequency $f$ is weak in the nematic range, however in the smectic range it is not so. In figure 3 we show $\Delta V=V_{1}-V_{\perp}$ at $2 \mathrm{Mhz}$ and $7.5 \mathrm{Mhz}$ and the two curves are close to one another in the nematic phase. In the smectic phase, $V$ is strongly dependent of $f$. This permits to see very clearly the NA transition. 


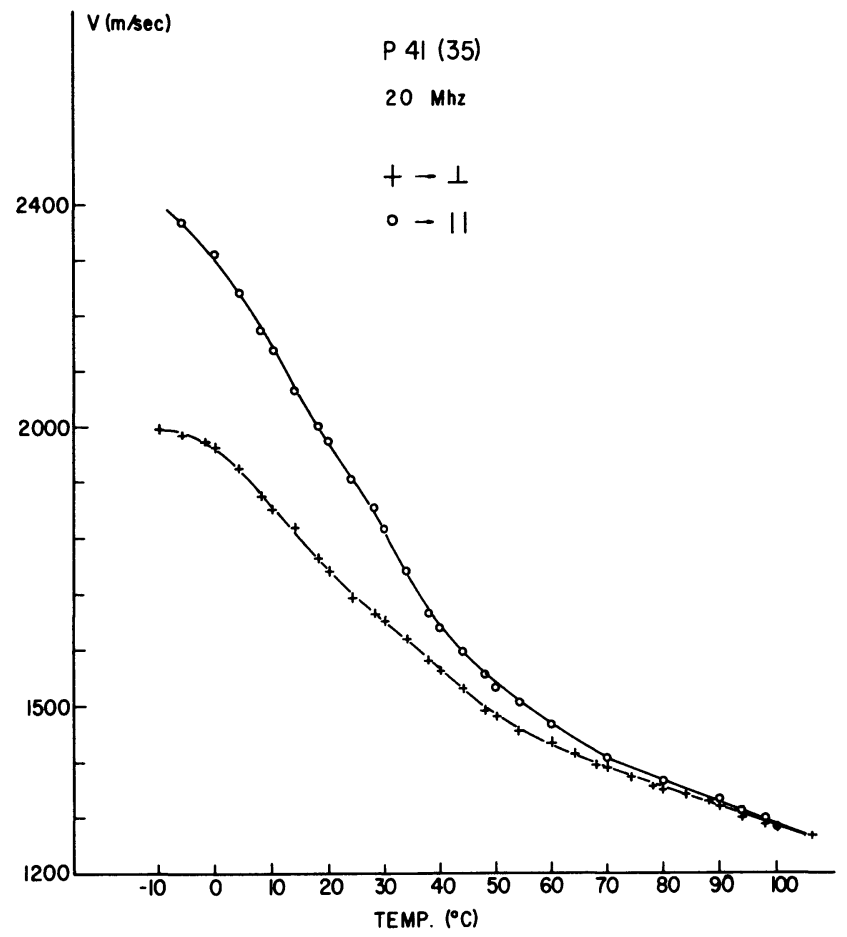

Fig. 1. - Longitudinal sound velocity at $2 \mathrm{MHz}$ in the directions parallel and perpendicular to the director.

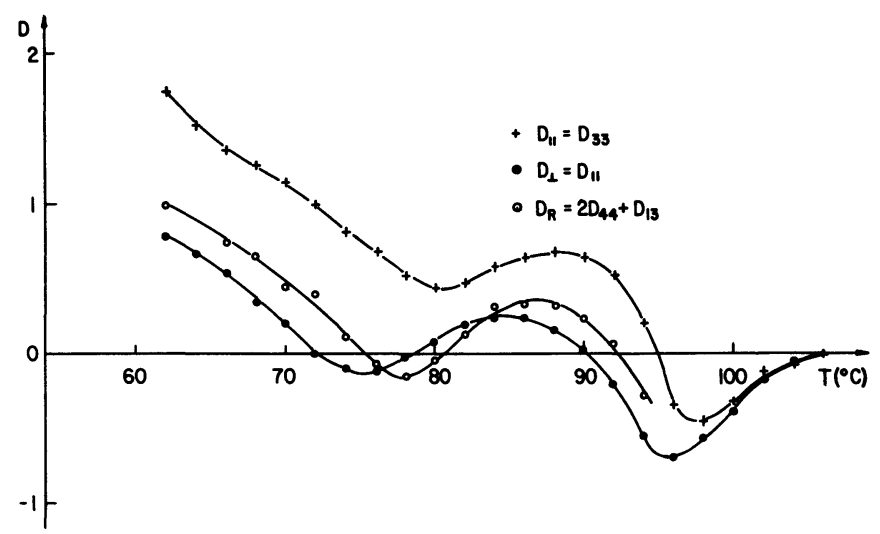

Fig. 2. - Relative absorption at $2 \mathrm{MHz}$ in the isotropic and nematic phases. $D_{\mathrm{R}}$ is equal to $D_{13}+2 D_{44}$ and obtained from the fit with expression (2).

We performed also measurements of $V$ and $D$ as a function of $\theta$, the angle between the wave vector and the director (Fig. 4).

2.2 THE SMECTIC A AND THE GLASS PHASES. - We were able to do measurements only at $2 \mathrm{MHz}$ because the large value of the absorption. This region is characterized by a regular 


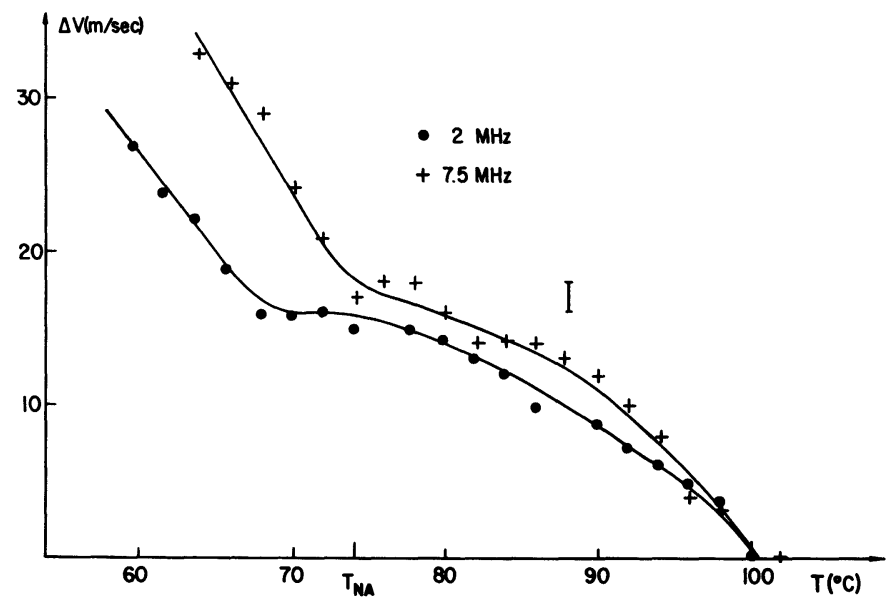

Fig. 3. - Velocity anisotropy $\Delta V=V_{1}-V_{\perp}$ at $2 \mathrm{MHz}$ and $7.5 \mathrm{MHz}$.

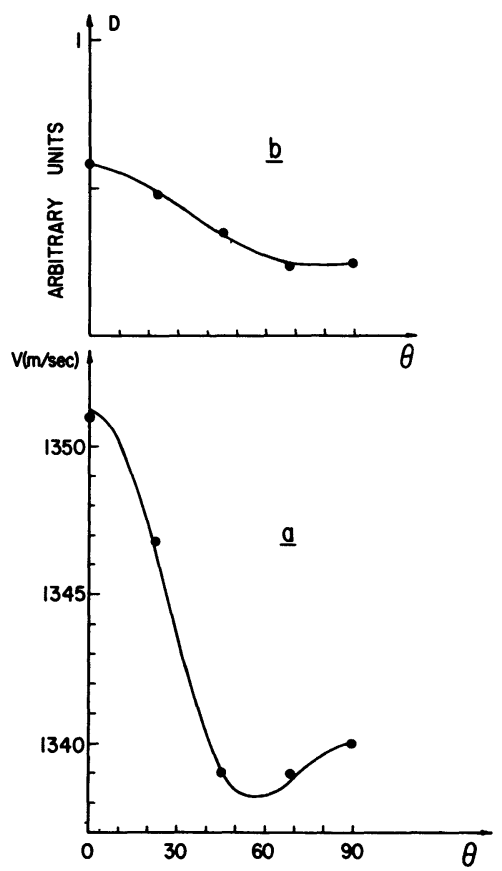

Fig. 4. - a) $V$ versus $\theta$, the angle between the wavevector and the director in the nematic phase ; b) $D$ versus $\theta$. The curves are calculated from the fit with expressions (1) and (2) $\left(T=82^{\circ} \mathrm{C}\right)$.

increase in $V_{\|}, V_{\perp}$ and $\Delta V$ (Fig. 1) and a broad maximum in $D$ (Fig. 5). The glass transition is indicated by small anomalies in $D_{\|}$and $D_{\perp}$ at around $5{ }^{\circ} \mathrm{C}$. The variations of $V$ and $D$ with $\theta$ were also measured (Fig. 6). It is clear that there is a continuous evolution of the system in the smectic A phase toward the glassy state. 


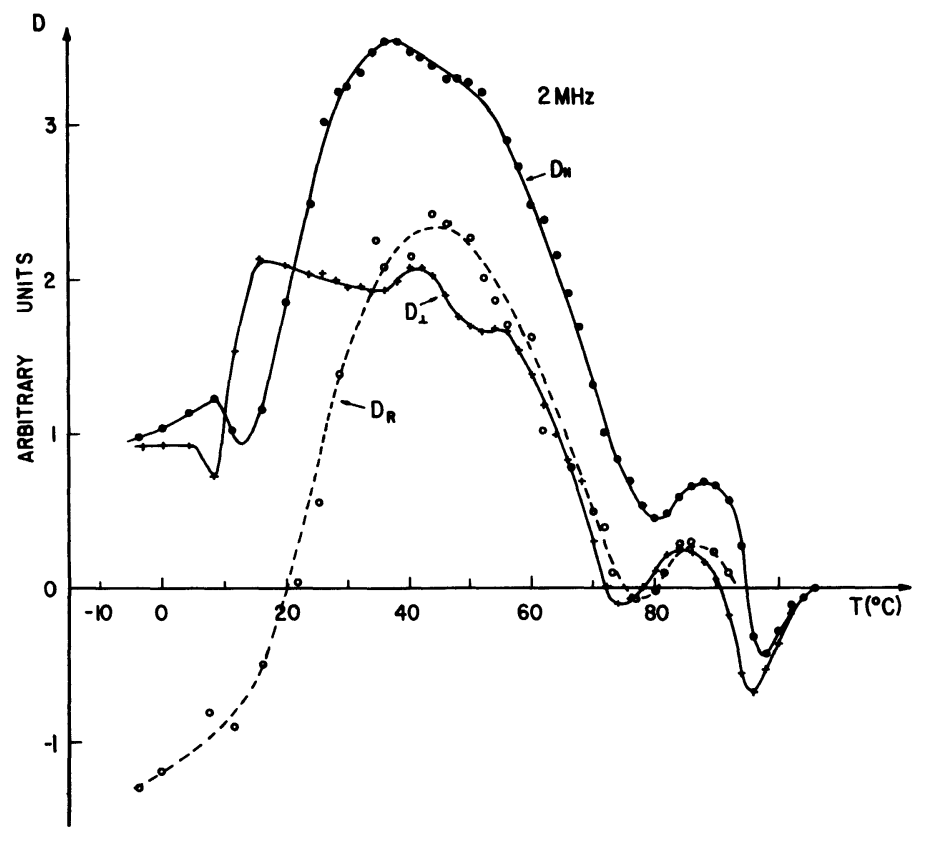

Fig. 5. - Relative absorption $D_{\mathrm{I}}$ and $D_{\perp}$ at $f=2 \mathrm{MHz}$. The coefficient $D_{\mathrm{R}}$ is equal to $D_{13}+2 D_{44}$ and obtained from the fit of the curve $D(\theta)$ with the expression (2).
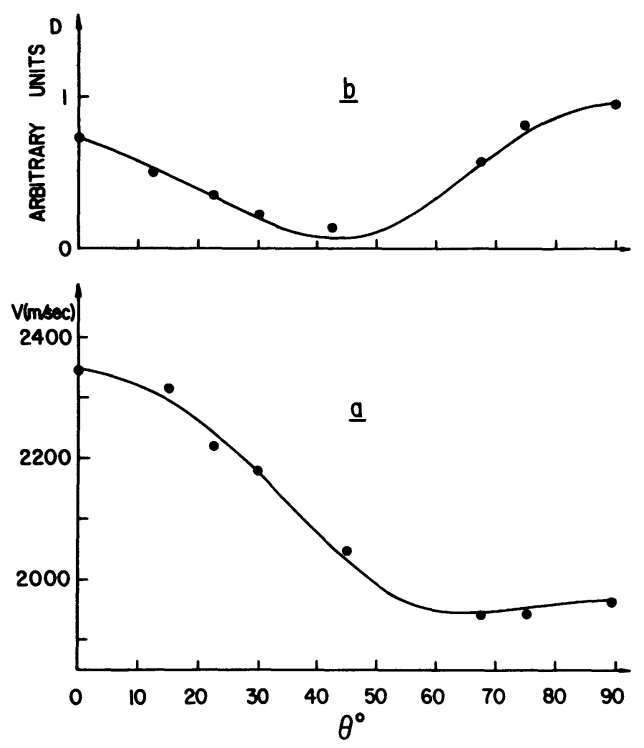

Fig. 6. - a) $V$ versus $\theta$ in the glass phase. b) $D$ versus $\theta$. The lines are calculated from the fit with expressions (2) and (3) $\left(T=-2^{\circ} \mathrm{C}\right)$. 


\section{Discussion and interpretation.}

3.1 The NEMATIC PHASE. - The main characteristics of the acoustical properties in the nematic phase are the following :

1) $V$ is dependent on $T$ and $\theta$, but practically not on $f$, in the range $2-9.3 \mathrm{MHz}$.

2) The velocity anisotropy $\left(10^{-2}\right)$ is much larger than in the monomer liquid crystals even in the $100 \mathrm{MHz}$ range [6].

3) We do not observe any anomaly in $V$ neither in $D$ at the IN and NA transitions, contrary to the monomer liquid crystals. The strong increase of $D$ near these transitions is completely absent.

We can interpret all these facts if one admits that the nematic phase is characterized by the condition $\omega \tau \gg 1$, where $\tau$ is the relaxation time. Following the theoretical analysis of Jahnig [7] the nematic phase at high frequency will have a viscoelastic behavior and not the hydrodynamic one that is observed at low frequency. Consequently, the system is now characterized by five elastic constants $C_{11}, C_{13}, C_{12}, C_{33}$ and $C_{44}$ and the acoustical absorption by three coefficients.

The maximum in $D(T)$ observed at 2 and $3.5 \mathrm{MHz}$ indicates a relaxation mechanism. The maxima in $D_{\perp}$ and in $D_{\|}$do not occur exactly at the same temperature if it possible to see in figure 2. For $D_{\perp}$, one finds that the maximum is near $85^{\circ} \mathrm{C}$ at $2 \mathrm{MHz}$ and near $90{ }^{\circ} \mathrm{C}$ at 3.5 $\mathrm{MHz}$. We conclude that the relaxation time decreases if $\mathrm{T}$ increases. This gives $\tau \sim 8 \times 10^{-8} \mathrm{~s}$ at $85^{\circ} \mathrm{C}$ and $\tau \sim 4.4 \times 10^{-8} \mathrm{~s}$ at $90^{\circ} \mathrm{C}$. The origin of this relaxation cannot be due to the slowing down of the order parameter or its fluctuations but to molecular mechanism like conformational relaxation of the alkyl chains or of the backbone in our case. We note also that for this kind of relaxation it was found that at room temperature $\tau \sim 10^{-8} \mathrm{~s}$ in MBBA [8] and in p-methoxy $\mathrm{p}^{\prime} \mathrm{n}$ butylaxoxy benzene [9]. Taking into account the difference in temperature, we find that $\tau$ is much larger in this polymer liquid crystal than in monomer liquid crystal, at least by one order of magnitude. The fact that the molecules are linked by the backbone makes the response of the system to external perturbation much slower.

In a uniaxial system, the longitudinal velocity as a function of $\theta$ is dependent on the $C_{11}, C_{13}, C_{33}$ and $C_{44}$ coefficients. However the anisotropy is relatively small, and since $C_{44}$ is certainly much lower than the other coefficients (see the following section), and $C_{11} \sim C_{13} \sim C_{33}$ we express the velocity $V$ by [2] ( $\rho$ is the density)

$$
V^{2}=\frac{1}{\rho}\left[A-2 C \cos ^{2} \theta+B \cos ^{4} \theta\right]
$$

with $A=C_{11}, C=C_{11}-C_{13}$ and $B=C_{11}+C_{33}-2 C_{13}$ as in a smectic A phase, contrarily to the monomer liquid crystals for which the expression $V=A+B \cos ^{2} \theta$ has been used [6]. The fit is good as it is possible to see in figure 4a. In figure 7 we plotted $B$ and $C$ versus $T . B$ and $C$ increases rapidly when $T$ decreases until they reach saturation below $85^{\circ} \mathrm{C}$. The value of $B$ at the saturation is about $10^{9} \mathrm{dyn} / \mathrm{cm}^{2}$ and that of $C$ is about $2.510^{8} \mathrm{dyn} / \mathrm{cm}^{2}$. These values are very similar to those measured in the smectic $A$ phase of monomer liquid crystals [10]. One observes very clearly in figure 7, the onset of the SmA phase by the very rapid increase of $B$ and $C$ at $3.5 \mathrm{MHz}$ below $T_{\mathrm{NA}}$. Near the NI transition temperature, $B \sim 0$ and $C<0$, as found in a monomer nematic phase. It is not clear why $B$ and $C$ are so different in the case of monomer and polymer.

The dependence of the absorption coefficient $D$ with the angle $\theta$ is given by [2]

$$
D=D_{11} \sin ^{2} \theta+D_{33} \cos ^{2} \theta+\left(4 D_{44}+2 D_{13}-D_{11}-D_{33}\right) \cos ^{2} \theta \sin ^{2} \theta \text {. }
$$


From a fit with this expression, we get the coefficient $D_{\mathrm{R}}=2 D_{44}+D_{13}$ which is plotted in figure 2. The three curves $D_{\|}(T)=D(\theta=0), D_{\perp}(T)=D(\theta=90)$ and $D_{\mathrm{R}}(T)$ have the same shape but with the maximum not exactly at the same temperature. However the three temperatures are sufficiently near that one can assume that the same relaxation mechanism is involved. It is clear that the background is in fact the continuation of the absorption curve of the SmA phase, and we shall interpret it as related essentially to the freezing of the backbone motion. (See following Sect.). Thus, the relaxation mechanism in the nematic phase is of intramolecular nature [7], recalling that a molecule is made of the backbone plus the mesogenic units. Because of the relatively large size of the molecule, it is understandable that the relaxation time is also large.

We conclude this section noting that in this polymer liquid crystal it is possible to study the high frequency limit at relatively low frequency, which is difficult to do in monomer liquid crystals.

3.2 The SMectic A PHASE AND THE Glass STATE. - In these phases, the behavior is quite different from that found above in the nematic phase. The phases are characterized by :

1. The continuous increase of the velocity (in all the directions) and of the anisotropy when $T$ decreases. Around $-14^{\circ} \mathrm{C}$, in the glass state $\Delta V$ is equal to $400 \mathrm{~m} / \mathrm{s}$ and the values of $V_{\|}$and $V_{\perp}$ are typical of a polymer.

2. The broad maximum in $D_{\|}$and $D_{\perp}$ around $40^{\circ} \mathrm{C}$. But $D_{\perp}$ is much structured than $D_{\|}$. Beside the maximum at $40{ }^{\circ} \mathrm{C}$, it seems that $D_{\perp}$ exhibits two other maxima.

These results can be interpreted as a dynamic glass transition which begins to develop at the onset of the smectic A phases. Immediately below $T_{\mathrm{NA}}, V$ is an increasing function of $\mathrm{f}$ and immediately above $V$ is approximately constant. At $2 \mathrm{MHz}$, this means that for $T \geqslant T_{\mathrm{NA}}$, one has $\omega \tau \gg 1$ but for $T \leqslant T_{\mathrm{NA}}$ the situation is $\omega \tau \ll 1$. In other words, there is a jump of $\tau$ from $\tau \gg \frac{1}{\omega}$ to $\tau \ll \frac{1}{\omega}$ in crossing the transition temperature $T_{\mathrm{NA}}$. Although the relaxation has a molecular origin as in the nematic phase, the system response in the SmA phase is faster than in the nematic. It is very likely that the relaxation does not imply the same type of molecular motion in the two phases (see below).

The analysis of the curves $V(\theta)$ has been made using two different expressions. In the glass state, we have used the complete expression of the longitudinal velocity in a uniaxial medium $^{2}$

$$
\begin{aligned}
V^{2}= & \frac{1}{2 \rho}\left(C_{11} \sin ^{2} \theta+C_{33} \cos ^{2} \theta+C_{44}\right)+ \\
& +\frac{1}{2 \rho}\left\{\left[\left(C_{11}-C_{44}\right) \sin ^{2} \theta+\left(C_{44}-C_{33}\right) \cos ^{2} \theta\right]^{2}+4 \sin ^{2} \theta \cos ^{2} \theta\left(C_{13}+C_{33}\right)^{2}\right\}^{\frac{1}{2}}
\end{aligned}
$$

By fitting the experimental results with (3), we determined the four coefficients $C_{11}, C_{13}, C_{33}$ and $C_{44}$. Above $20^{\circ} \mathrm{C}$ the coefficients $C_{44}$ is so small that the use of (3) as it stands is meaningless and we used (3) making $C_{44}=0$. When the three coefficient $C_{11}, C_{13}$ and $C_{33}$ are found to be near one another, we come back to the expression (1) (between $70^{\circ} \mathrm{C}$ and $50^{\circ} \mathrm{C}$ ). The results are shown in figures 7 and 8 . In figure 7 , we displayed the coefficients $C=C_{11}-C_{13}$ and $B=\left(C_{44}+C_{33}-2 C_{13}\right)$ down to $50^{\circ} \mathrm{C}$ and in figure 8 , the four coefficients $C_{11}, C_{33}, C_{13}$ and $C_{44}$ from $40^{\circ} \mathrm{C}$ to $-6{ }^{\circ} \mathrm{C}$. The coefficients $C_{11}$ and $C_{33}$ increase continuously when $T$ decreases, as it is expected for a continuous transition to a solid phase. The coefficient $C_{13}$ behaves exactly like $C_{11}$ until $T \sim 25^{\circ} \mathrm{C}$. From $T=T_{\mathrm{NA}}$ to this last temperature the difference $C_{11}-C_{13}$ is constant and equal to $2 \times 10^{8} \mathrm{dyn} / \mathrm{cm}^{2}$. However, below $25^{\circ} \mathrm{C}$, there is a change in the slope of $C_{13}$ : now 


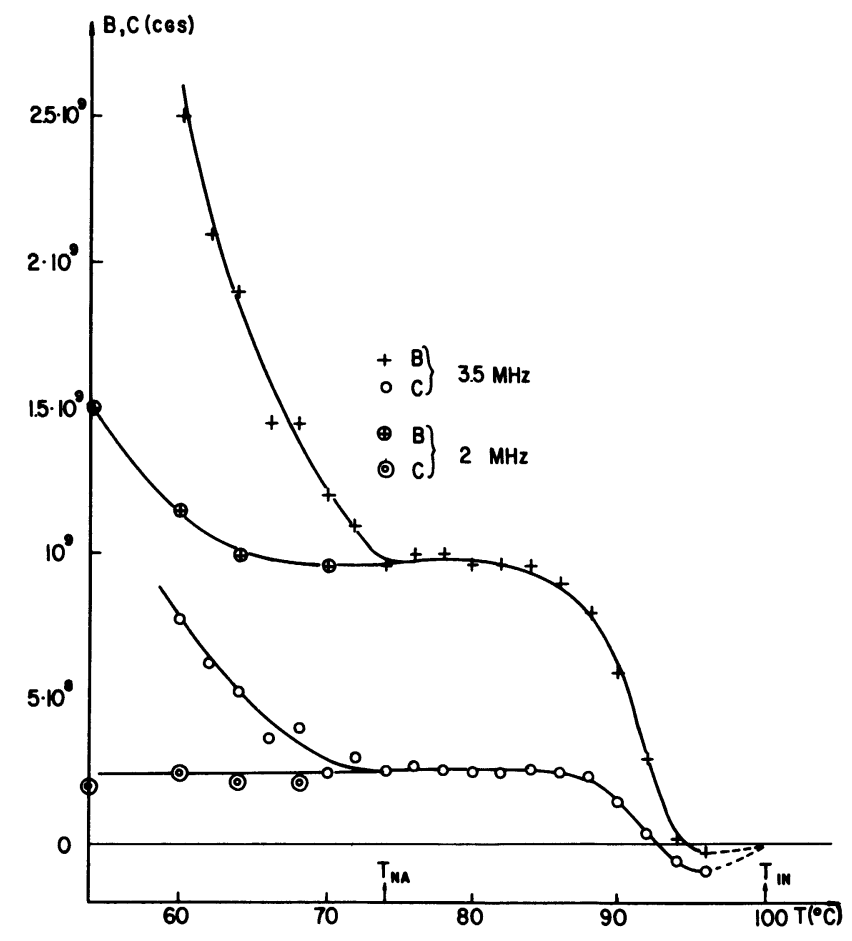

Fig. 7. $-B$ and $C$ versus temperature in the nematic phase and the upper part of the smectic phase at 3.5 $\mathrm{MHz}$ and $2 \mathrm{MHz}$. In the nematic phase, $B$ and $C$ are practically independent of the frequency.

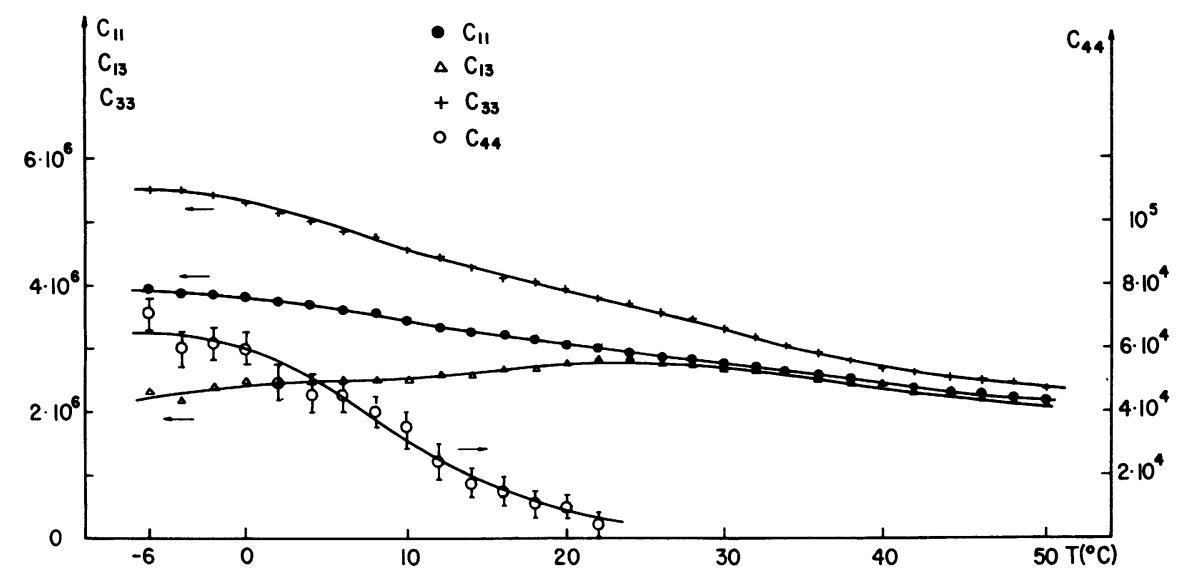

Fig. 8. - Elastic coefficients $C_{11}, C_{13}, C_{33}$ and $C_{44}$ in the smectic A and the glass phases. To get the values of the $C_{i j}$ in CGS, multiply by $10^{3}$.

$C_{13}$ decreases, if $T$ decreases. The behavior of the $C_{i j}$ is consistent with the picture of a system becoming harder and harder when $T$ decreases. For example, consider a cubic element of the material and apply three constraints $X_{1}, X_{2}$ and $X_{3}$ such that the strains $\chi_{1}$ and $\chi_{2}$ are kept null but $\chi_{3} \neq 0$. The strain $\chi_{3}$ is given by $X_{3} / C_{33}$ and the stress $X_{1}=X_{2}$ that we 
have to apply to keep $\chi_{1}=\chi_{2}=0$, is $C_{13} X_{3} / C_{33}$. When the system becomes harder, $\chi_{3}$ decreases and $X_{1}$ and $X_{2}$ do the same.

The absorption is analysed with the help of (2), as above. $D_{\mathrm{R}}=2 D_{44}+D_{13}$ is plotted with $D_{\|}=D_{33}$ and $D_{\perp}=D_{11}$. Contrary to the nematic phase, the three coefficients exhibit very different behaviors. The three have their maximum approximately at the same temperature, but only $D_{\perp}$ is structured, as we mentioned above. $D_{\mathrm{R}}$ decreases strongly in the glass phase, becoming negative i.e. smaller than the absorption at $106^{\circ} \mathrm{C}$. This also can be viewed as a consequence of the solid like behavior of the solid below about $25^{\circ} \mathrm{C}$ at this frequency. The molecules can be displaced with small dissipation in the direction parallel to the director (perpendicular to the smectic planes). The backbone can follow easily this kind of motion if one admits, following the work of the French group [1] that the backbone is confined along the smectic layers.

The common and large maximum of the three $D$ coefficients is probably related to the freezing of the backbone motion, as the well known structural relaxation of liquids [11]. However, in our case the particular shape of $D_{\perp}(T)$ (which can be seen as the superposition of three peaks) gives to think that the relaxation process is more complicated. Even the $D_{\|}(T)$ curve shows two small shoulders on both sides of the maximum. However the imprecision in determining $D_{\mathrm{R}}(T)$ does not give the possibility to detect small anomalies and only the maximum is clearly seen.

One of the most interesting result of the neutron scattering [1] is that the backbone becomes localized between the smectic layers when the temperature is decreased. It seems that there is a coupling between the confinement of the backbone and the SmA ordering. Thus we can admit that the transition to the glass state implies the freezing of several modes of motion, those associated with the backbone and those with the mesogen units. However, at the present stage, it is not possible to give a specific assignment to the different relaxations.

To conclude this section, we can say that the sample gets different properties when it becomes layered. All these properties can be related to its evolution toward the more compact state, the glass phase : the strong dependence of $V$ with the frequency observed immediately below $T_{\mathrm{NA}}$; the increase of velocity anisotropy and the temperature dependence of the $C_{i j}$ coefficients; the strong absorption, above the glass transition temperature, characteristic of the dynamic character of the acoustic measurements; the different shapes of the $D$ coefficients involving different molecular motions, mainly controlled by the backbone.

\section{References}

[1] Keller P., Carvalho B., Cotton J. P., Lambert M., Moussa F. and Pepy G., J. Phys. Lett. 46 (1985) L1065;

Moussa F., Cotton J. P., Hardouin F., Keller P., Lambert M. and Pepy G., J. Phys. France 48 (1987) 1079.

[2] Mryano K. and Ketterson J. P., Phys. Acoust. Ed. W. P. Mason and R. N. Thurston (Academic, New York) 1979, Vol. 14.

[3] Kruger J. K., Peetz L., Siems R., Unruh H. G., Eich M., Hermann-Schonherr O. and Wendorf J. H., Phys. Rev. A 37 (1988) 2637.

[4] Mauzac M., hardouin F., Richard H., Achard M. F., Sigaud G. and Gasparoux H., Eur. Polym. J 22 (1986) 137.

[5] Benguigui L. and Ron P., Mol. Cryst. Liq. Cryst. 153 (1987) 241.

[6] Muller M. E., Luthi B. and Stephen M. J., Phys. Rev. Lett. 28 (1972) 799 ;

BACRI J. C., J. Phys. France (1974) 605.

[7] JAHnig F., Z. Phys. 258 (1973) 199. 
[8] Eden D., Garland C. W. and Williamson R. C., J. Chem. Phys. 58 (1973) 1861.

[9] Candau S., Martinoty P. and Zana R., J. Phys. Lett. 36 (1975) L13.

[10] Collin D., Gallani J. L. and Martinoty P., Phys. Rev. A 34 (1986) 2255.

[11] Litovitz T. A. and Davies C. M., Phys. Acoust. Ed. W. P. Mason and R. N. Thurston (Academic, New York) 1979, Vol. IIA. 